\title{
Uluslararası Göç ve Güvenlik, Editörler: Doç. Dr. Gökhan Telatar - Doç. Dr. Umut Kedikli, Ankara, Nobel Yayınları, 2019, 274 s. ISBN: 978-605-033-137-0
}

Turgut Erkam Nalbant ${ }^{1}$ (i)

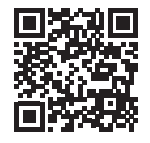

'Sorumlu yazar/Corresponding author: Turgut Erkam Nalbant, (Yüksek Lisans Öğrencisi), İstanbul Üniversitesi, Sosyal Bilimler Enstitüsü, Avrasya Araştırmaları Anabilim Dalı, İstanbul, Türkiye.

E-posta: turguterkam@gmail.com ORCID: 0000-0001-8589-2607

Başvuru/Submitted: 06.08 .2020 Kabul/Accepted: 08.08.2020

Atıf/Citation: Nalbant, Turgut Erkam. "Uluslararası Göç ve Güvenlik." Gökhan Telatar ve Umut Kedikli'nin Uluslararası Göç ve Güvenlik adlı eserin tanıtımı. Avrasya Incelemeleri Dergisi - Journal of Eurasian Inquiries 9. 2 (2020): 309-313.

https://doi.org/10.26650/jes.2020.020

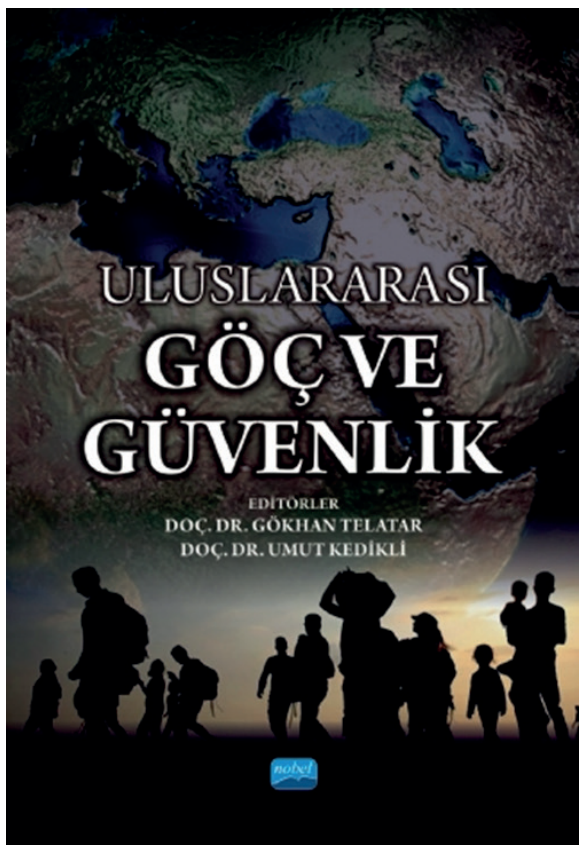


“Uluslararası Göç ve Güvenlik” adı altında on iki akademisyenin kaleme aldığı on makaleden oluşan kitabın editörlüğünü, aynı zamanda kitapta makaleleri olan Gökhan Telatar ${ }^{1}$ ve Umut Kedikli² yapmıştır.

Eser, Gökhan Telatar ve Umut Kedikli'nin ortaklaşa kaleme aldıkları 'giriş' bölümüyle başlamaktadır. Yazarlar bu bölümde eserin yazılış amacının göçün bir güvenlik meselesi olduğu düşüncesinden hareket ederek farklı boyutlarını kapsamlı bir şekilde analiz etmek olduğunu belirtmişlerdir. Bu bağlamda göç olayının artık uluslararası ilişkilerin en önemli gündem maddesi olması nedeniyle bu konunun irdelenmesi gerektiği de vurgulanmıştır. Giriş bölümünde ayrıca göç olgusunun, göç edenler ve göç edilen uluslar için ortaya çıkan bireysel ve toplumsal güvenlik sorunlarının neler olduğu, bu sorunları ulusal ve uluslararası yaklaşımların nasıl ele aldığı gibi konulara ve her bölüm hakkında tanıtıcı kısa bilgilere yer verildiği görülmektedir. Kitabın sonuna ‘dizin’ eklenmiş ve dizinden sonra bölüm yazarlarının k1sa özgeçmişlerine yer verilmiştir.

Kitapta yer alan bölüm başlıkları ve yazarlar şunlardır:

1- Göç ve Güvenlik: Kavramsal ve Teorik Bir Analiz, Doç. Dr. Gökhan Telatar, s. 7-38

2- Uluslararası Hukuksal ve Kurumsal Düzenlemeler Çerçevesinde Göç Olgusu, Prof. Dr. Mehmet Dalar, s.38-60

3- Uluslararası Göçün Ekonomi Politiği, Arş. Gör. Caner Kalaycı, s. 61-83

4- Bir Güvenlik Sorunu Olarak Düzensiz Göçe Bağlı Göçmen Kaçakçılığı, Doç. Dr. Umut Kedikli, s. 85-111

5- Göç, Uyum, Tehdit ve Çöküş: Yeni Toplumsallıklar İnşası Mümkün mü? Doç. Dr. Adem Să̆ır, s. 113-136

6- Kadın Göçü ve İnsan Güvenliği, Dr. Öğr. Üyesi Cengiz Kılıç, Prof. Dr. Ayfer Aydıner Boylu, Prof. Dr. Gülay Günay, s. 137-156

7- Göç ve Uluslararası İşbirliği, Arş. Gör. Mehmet Akif Türkdoğan, s. 157-179

8- Avrupa Birliğinin Göç Politikası: Göçün İnsani Olmayan Güvenlikleştirilmesi, Doç. Dr. Ekrem Yaşar Akçay, s. 181-207

1 Doç. Dr. Gökhan Telatar, Uludağ Üniversitesi’nde “Orta Asya'da Güvenlik Sorunları, 11 Eylül Sonrası Rusya-ABD Rekabeti ve Bunun Orta Asya Güvenliğine Etkileri” başlıklı teziyle 2005 yılında yüksek lisansını tamamlamıştır. Abant İzzet Baysal Üniversitesi ve Ankara Üniversitesi'nde araştırma görevlisi olarak görev yapmış, 2009 yılında Susakawa Genç Liderler Burs Fonu uluslararası araştırma ödülünü kazanarak University of Maryland'de misafir araştırmacı olarak bulunmuştur. 2011 yılında Ankara Üniversitesi’nde “11 Eylül Sonrası Amerikan Dış Politikasında Hegemonyanın Yeniden İnşası” başlıklı teziyle doktora eğitimini tamamlamıştır. 2017 yılından bu yana Abant İzzet Baysal Üniversitesi Uluslararası İlişkiler Bölümü’nde Doç. Dr. olarak görev yapan ve çok sayıda yayını bulunan Gökhan Telatar, çalışmalarında son dönem göçler konusu üzerine yoğunlaşmıştır.

2 Doç. Dr. Umut Kedikli, 2005 yılında “Birleşmiş Milletler ve Meşru Müdafaa Hakkı” başlıklı tez çalışmasıyla Ankara Üniversitesi’nde yüksek lisans programını, 2011 yılında aynı üniversitede "Devletlerin Uluslararası Terörizme Desteği bağlamında Uluslararası Sorumluluğu” başlıklı teziyle de doktora programını tamamlamıştır. Karabük Üniversitesi Uluslararası İlişkiler Bölümü’nde görev yapmaktadır. Umut Kedikli'nin uluslararası güvenlik, terörizm ve insan hakları konularında çok sayıda makalesi yayınlanmıştır. 
9- Türk Kamu Yönetiminde Göç Örgütlenmesi ve Politikası, Doç. Dr. Mustafa Altunoluk, s. 209-244.

10-İç Çatışmalar ve Göç, Doç. Dr. Sezai Özçelik, s. 245-264

“Göç ve Güvenlik: Kavramsal ve Teorik Bir Analiz” başlıklı birinci bölüme Gökhan Telatar, göç-güvenlik ilişkisinin kapsamlı bir değerlendirmesini yapmayı amaçladığını belirterek başlamıştır. Güvenlik kavramını ve bu kavramın tarihsel süreçteki evrimini, uluslararası ilişkilerde güvenliğe ilişkin teorik yaklaşım modellerinden olan geleneksel, çoğulcu, genişletilmiş, eleştirel ve birey merkezli güvenlik yaklaşım kavramlarını, bu yaklaşımlarla oluşturulan ulusal ve uluslararası kurumlardaki değişimleri anlatmıştır. Ayrıca göçün bir güvenlik sorunu oluşturması, devletlerin göç öncesinde, göç sırasında ve sonrasında güvenliğin sağlanmasındaki tutum farklılıkları ve nedenleri, ulusal ve uluslararası göçle ilgili kurum ve kuruluşların fonksiyonları ele alınmıştır. Bu bölümün sonuç kısmında yazar, göç ve güvenlik hususunda değerlendirmelerde bulunmuştur.

"Uluslararası Hukuksal ve Kurumsal Düzenlemeler Çerçevesinde Göç Olgusu” başlıklı ikinci bölümde yazar Mehmet Dalar, göç olgusunu uluslararası hukuksal ve kurumsal düzenlemeler çerçevesinde ele almıştır. Yazının giriş kısmında ulusal ve uluslararası kurumsal ve hukuksal düzenlemeler anlatılmıştır. Daha sonraki kısımlarda 'göç, göçmen, işçi göçü, yasa dışı göçmen, düzensiz göç, mülteci, şartlı mülteci, sığınmacı, kısa dönem mülteci/sığınmacı, uzun dönem mülteci/sığınmacı, geçici koruma, ikincil koruma' gibi kavramların Türkiye ve uluslararası hukuk içinde ne anlamlara geldiği incelenmiş ve bu kavramların uluslararası sözleşmelerde nasıl yer aldığı belirtilmiştir. Ayrıca "Uluslararası Göç Örgütü ve Birleşmiş Milletler Mülteciler Yüksek Komiserliğì” teşkilatlarının kuruluşu, görev alanları, bu iki kurumun ilişkisi gibi konular ele alınmış; sığınma ve iltica hakkının tanınması ve sonuçlarına değinilmiştir. Sonuç kısmında uluslararası sözleşmelerin devletler üzerindeki hukuki etkileri anlatılarak dünyada en fazla uluslararası göçe maruz kalan Türkiye'nin de taraf olduğu uluslararası sözleşmelerin gerektirdiği Türk Hukuk Sistemi'nde yapılan düzenlemeler hakkında bilgiler verilmiştir.

“Uluslararası Göçün Ekonomi Politiği”" ismini taşıyan üçüncü bölümde Caner Kalaycı amacının ekonomi politik temelde uluslararası göç ve güvenlik ilişkisini analiz etmek olduğunu belirtmektedir. Çalışmada öncelikle göç ve ekonomi ilişkisi, sonrasında ekonomi politik analizin dayandığı felsefi temellere değindiği görülmektedir. Yazar, on dokuzuncu yüzyıldan günümüze göç ve ekonomi ilişkisi üzerine yaklaşımların tarihi seyrini anlatmış, Marksist ve kapitalist felsefi görüşlerin göç olgusuna bakışlarını karşılaştırmış ve bu felsefi görüşlerin sonuçlarının göçmenler üzerindeki sonuçları hakkında bilgiler vermiştir. Sonuç kısmında uluslararası göçlerin hem göç alan ülke ve vatandaşlarının hem de göçmenler ve göç veren ülkeler açısından kalkınma konusunda bir güvenlik meselesi doğurduğu tezi savunulmuştur.

Dördüncü bölüm olan "Bir Güvenlik Sorunu Olarak Düzensiz Göçe Bağlı Göçmen Kaçakçılı̆̆gı”nı kitabın iki editöründen biri olan Umut Kedikli yazmıştır. Bölümün giriş kısmında 
devletlerin sınırları belli bir varlığa dönüşmesi, devletlerarasındaki ekonomik, sosyal ve siyasal gelişme farklılıklarının göç hareketliliğini hızlandırması neticesinde alınan kısıtlayıcı kararların etkilerinin düzensiz göçe neden olması ve buna bağlı olarak göçmen kaçakçılığında çeşitli yöntemlerin oluşması anlatılmıştır. Zorunlu ve düzensiz göç kavramları üzerinde durulmuş, bu kavramların oluşma süreçleri belirtilmiştir. Göçmen kaçakçılığının oluşması, kaçakçılık yöntemleri ve kaçakçılık bedelleri hakkında bilgiler verilerek göçmen kaçakçılığının Türk Ceza Kanunundaki cezai karşılığına vurgu yapılmıştır. Birleşmiş Milletlerin Aralık 2000'de hazırladığı Polermo Sözleşmesi’nde insan kaçakçılığının örgüt suçu olduğu belirtilerek bu sözleşme hakkında bilgi verilmiştir. Bu bölümde dünya göçmen kaçakçılığı güzergâhları ve bu güzergâhlar üzerinde Türkiye'nin yeri ayrıntılı olarak anlatılmıştır. Ayrıca göçmen kaçakçılığında güvenlik sorunları ve göçmen kaçakçılığı ile mücadele başlıkları açılarak içerisinde Türkiye'nin de bulunduğu göç güzergâhları belirtilmiştir. Sonuç bölümünde ise bu sorunlara çözüm önerileri sunulmuştur.

“Göç, Uyum, Tehdit ve Çöküş: Yeni Toplumsallıklar İnşası Mümkün mü?” başlıklı beşinci bölümde Adem Sağır daha çok iki binli yılların sonunda gelişen Suriye örneğinde olduğu gibi iç savaşların sonucunda ortaya çıkan kitlesel göçleri konu edinmiştir. Bu kitlesel göçlerin "risk toplumu", "güvensizlik", "çatışma”, "kültürel ayrışma”, "iki kültür arasında bocalama" gibi kavramları ortaya çıkarabileceği belirtilmektedir. Ayrıca Suriyeli göçmenlerin Türkiye’deki uyum ve uyumsuzluğu, bir güvenlik tehdidi oluşturup oluşturmayacağı, Türk halkında toplumsal tepkiye neden olup olmayacağı gibi varsayımlar üzerinde de durulmuştur.

Cengiz Kılıç, Ayfer Aydıner Boylu ve Gülay Günay’ın ortaklaşa kaleme aldığ Göçü ve İnsan Güvenliği” başlıklı altıncı bölümün girişinde, göç olgusunun tarifiyle birlikte “demografik, sosyolojik, ekonomik, politik ve psikolojik yaklaşım” kavramları üzerinde durulmuştur. Son yirmi yılda göç edenlerin yarısını kadınların ve kız çocuklarının oluşturduğu tespit edilerek kadın göçünün analizi yapılmaya çalışılmıştır. Cinsiyet ve toplumsal cinsiyetin farklı kavramlar olduğu ve göç çalışmalarının tarihi sürecinde kadınların özel olarak ele alınıp incelenmesi gereken bir alan oluşturduğu belirtilmiştir. Bu kavramlar çerçevesinde kadın göçünün konumlandırılmasına çalışılan bu bölümde ayrıca kadın göçünün nedenlerine, kadınların çalıştıkları iş kollarına, karşılaştıkları sorunlara ve göçün kadınlar üzerindeki etkilerine değinilmiş; göç güvenliği ve göç sonrası istihdamda kadın-erkek eşitsizliğine vurgu yapılarak sonuç kısmında da bu eşitsizliğe çözüm olacak öneriler sunulmuştur.

“Göç ve Uluslararası İşbirliği” başlıklı yedinci bölüm, Mehmet Arif Türkdoğan tarafından kaleme alınmıştır. Yazının giriş kısmında, tarihsel süreç içerinde göçün unsurlarına yönelik oluşturulan uluslararası örgütlerin ve uluslararası işbirliğine yönelik çalışmaların inceleneceği belirtilmiştir. Makalede 1919 yılından günümüze kadar olan tarihsel sürecin analizi 19191945, 1945-1999 ve 1999 sonrası olmak üzere üç döneme ayrılarak yapılmıştır. Bu süreçte kurulan uluslararası örgütler ve yapılan işbirliği çalışmaları ayrı ayrı değerlendirilmiş, küresel işbirliği çalışmaları kapsamında "New York Deklarasyonu”, "Küresel Mutabakatlar”, "Bölgesel 
İstişare Süreçleri (Almatı, Lima, Pueabla, Bali, Prag)" incelenmiş ve bu çalışmaların sonuçları hakkında bilgiler verilmiştir. Sonuç kısmında uluslararası örgütlerin devletleri bağlayıcı yasal düzenlemeleri ortaya koyamaması ve devletlerin de güvenlik ve egemenlik kaygıları ile bağlayıcı düzenlemelere yanaşmaması sonucu göç yönetiminde son sözün hâlâ devletlere ait olduğu vurgulanarak uluslararası ilişkilerin daha fazla artırılması gerekliliği üzerinde durulmuştur.

Ekrem Yaşar Akçay’ın kaleme aldığı “Avrupa Birliğinin Göç Politikası: Göçün İnsani Olmayan Güvenlikleştirilmesi” başlıklı sekizinci bölümde, Avrupa’da göç unsurunun ne tür süreçlerden geçtiği ve göç politikalarında nasıl bir değişim yaşandığı analiz edilmektedir. $\mathrm{Bu}$ süreçler ve politika değişiklikleri “Maastricht Anlaşması öncesi”, "Maastricht Anlaşması'ndan Lizbon Anlaşmasına Kadar”, "Lizbon Anlaşması'ndan Arap Baharına Kadar” ve “Arap Baharı Sonrası" şeklinde dönemlere ayrılarak incelenmiş ve Arap Baharı sonrasında yapılan işbirlikleri hakkında bilgi verilmiştir. Ayrıca Avrupa Birliği’nin yasa dışı göçle mücadelede uyguladığı politikaların hukuki değerlendirmesi yapılarak Avrupa Birliği ülkelerinin göç politikalarında yapmaları gereken politika değişikliği hakkında sonuç bölümünde öneriler sunulmuştur.

Mustafa Altunok’un yazdığı dokuzuncu bölüm “Türk Kamu Yönetiminde Göç Örgütlenmesi ve Politikası”nın giriş kısmında, sürekli iç ve dış kaynaklı göç alan ve veren bir ülke olarak Türkiye'nin tam bir göç ülkesi olduğu vurgulanmıştır. Yazıda göç olgusuna kamu politikası, kamu hukuku, kamu maliyesi, kamu personeli, kamu örgütü, kamu hizmeti, kamu düzeni ve kamu güvenliği penceresinden ayrı ayrı bakılarak, Türkiye’nin göç örgütlenmesi ve göç politikasını incelenmiş ve değerlendirmelerde bulunulmuştur. Ayrıca Göç İdaresi Genel Müdürlüğ̈̈’nün 2016-2019 arası mali görünüm tablosu çıkartılarak personel sayısı ile personel harcamalarındaki artışa dikkat çekilmiştir.

Sezai Özçelik'in kaleme aldığı "İç Çatışmalar ve Göç” başlıklı onuncu bölümde göçün nedenleri, etkileri, etkilenenleri ve sonuçları örnekler üzerinden değerlendirilmiş ve silahlı çatışmaların uluslararası göç olgusuna etkileri anlatılmıştır. Çeşitli kıtalardaki silahlı çatışmanın şekli, nedenleri, oluşumu ve yaygınlığı ele alınmış; çatışmaların bölgedeki istikrarın bozulmasına ve halk arasında büyük acılara sebep olması ve güvensizliğin oluşması gibi konular işlenmiştir. Bu iç çatışmaların Orta Doğu, Kafkasya, Balkanlar, Akdeniz ve Orta Asya gibi bölgelerde uluslararası çatışma hâline dönüşmesi sonucunda en fazla göç hareketliliğinin de buralarda yaşandığına dikkat çekilmiştir. Ayrıca bu durumun göç güzergâhında yer alan ülkemize yansımaları da değerlendirilmiştir.

Sonuç olarak bu eser uluslararası göç ve güvenlik alanında yetkin araştırmacılarla hazırlanan kapsamlı makalelerden oluşmaktadır. Göç ve güvenlik politikalarına ilgi duyanlar, üniversitelerin uluslararası ilişkiler bölümünde okuyan öğrenciler, alanı uluslararası ilişkiler olan öğretim üyeleri ile göç ve güvenlik örgütlerinde çalışanlar için başvuru niteliğinde bir eser olduğunu söyleyebiliriz. 
